\title{
Comparative study of antimicrobial activities of three tropical fruits in Southern India
}

\begin{abstract}
An antibiotic is an agent that can either kill or inhibit the growth of a microorganism. Antibiotics are key defence against disease causing microbes. Simultaneously pathogenic microbes develop resistance against antibiotics along with their side effects on target organisms. Plant-based chemical microbial compounds will be safer than synthetic chemical compounds. So finding new sources for antimicrobial activity is inevitable. Three plants in the southern parts of India, Ficus racemosa Linn., Passiflora edulis Sims and Morus alba Linn were selected for the present study. The leaves, barks and fruits were used for treating various ailments in folk remedies. In this study, ripe fruits of the selected plants were collected from Thiruvananthapuram district of Kerala state. Ethanolic extracts of fruits of these plants were used to study their potency against Candida albicans, Aspergillus niger, Pseudomonas aeroginosa, Streptococcus mutans, Staphylococcus aureus and Escherichia coli. The fruits of all the studied plants showed microbial growth inhibition at higher concentrations. Inhibitory action of the fruit extracts also varied. The study revealed that Morusalba extract is more effective against different microbes. The antimicrobial activities of the extracts were also compared with standard antibiotics. A concentration of $100 \mu \mathrm{l}$ Morus alba extract inhibited growth of $C a$ by $1.2 \mathrm{~cm}, E c$ by $1.1 \mathrm{~cm}$ and $S a$ by $1.3 \mathrm{~cm}$. P.edulis also inhibited growth of $E c$ by $1.2 \mathrm{~cm}, P a$ by $1.2 \mathrm{~cm}, S a$ by $1.0 \mathrm{~cm}$ and $S m$ by $1.2 \mathrm{~cm}$ at $50 \mu \mathrm{l}$ and the rate of inhibition is observed to be increasing with concentration. F.Racemosa inhibited the growth of $E c$ by $1.3 \mathrm{~cm}, P a$ by $0.5 \mathrm{~cm}$ and $S m$ by $1.5 \mathrm{~cm}$ at $100 \mu l$ concentration. The studied plants can be used for developing antibiotics, since plant-based antibiotics will be a blessing for the society.
\end{abstract}

Keywords: Ficus racemosa, Passiflora edulis, Morus alba, antimicrobial activity, zone of inhibition

\author{
Volume 3 Issue 5 - 2019
}

TG Madhuri, Jaya Divakaran Sarasamma

Department of Environmental Sciences, University of Kerala, India

Correspondence: Jaya Divakaran Sarasamma, Department of Environmental Sciences, University of Kerala, Karyavattom Campus, Thiruvananthapuram.PIN-69558I, India, Email jayvijayds@gmail.com

Received: May 16, 2019 | Published: September 06, 2019

\section{Introduction}

After the invention of the first antibiotic by Alexander Fleming, innumerable antimicrobial compounds have been developed from different sources. Unfortunately these can even act against non target organisms and kill normal defence bacteria in the bowel and vagina. This present scenario emphasizes the need for finding new sources, which are more effective, and with less side effects. Ficus racemosa, Passiflora edulis and Morus alba are tropical fruits with so many medicinal properties. It is doubtful whether the phytochemical potential of these plants were being properly exploited. Ficusracemosa Linn is included under the family Moraceae and has been extensively used in traditional medicine for a wide range of ailments. ${ }^{1}$ Its fruits are anti-diuretic, refrigerant, gastroprotective and used against cancer, scabies, leprosy etc. ${ }^{2}$ Passifloraedulis is a woody climber belonging to Passifloraceae and is used in homeopathic medicine for the treatment of insomnia, epilepsy, tetanus, muscle spasms etc. Nicolls ${ }^{3}$ extracted a compound with antimicrobial activity from different species of Passiflora and named it 'passicol'. Morus alba belongs to Moraceae family, its leaves and fruits are pharmaceutical and nutraceutical. Leaves are feedstock for silkworms. In traditional Chinese medicine, the fruits, leaves and bark are used against various ailments.

The aim of the present study is to assess the antifungal activity and antibacterial activity of the fruit extracts of Passiflora edulis Sims $^{4}$ (P.edulis), Morus alba Linn.(M.alba) and Ficus racemosa Linn. (F. Racemosa). Antimicrobial activity (antibacterial and antifungal activity) is evaluated to find out more safe, more effective and new sources of antibiotics to improve the health status of humanity. The study may help to popularize the use of such neglected fruits, the nature's blessings.

\section{Materials and methods}

\section{Sample collection}

The selected plants Passiflora edulis, Morus alba and Ficus racemosa were identified and the ripe fruits were collected from the homesteads of Thiruvananthapuram district, washed in distilled water, and brought to the laboratory in separate labelled polythene bags. Taxonomic identification was confirmed using registers in the library of Jawaharlal Nehru Tropical Botanical Gardens \& Research Institute, Palode and with accession No:15221 Passiflora edulis, 19582 Morus alba and 9881:Ficus racemosa.

\section{Preparation of fruit extracts}

Ethanolic extracts were prepared from air dried and crushed fruit samples using soxhlet apparatus. The extracts were filtered using Whatman filter paper (No.1) and concentrated in vacuum under atmospheric pressure using rotary flask evaporator, and then dried in a dessiccator.

\section{Test organism}

The antifungal activity against Candida albicans $(\mathrm{Ca})$, Aspergillus niger(An) and antibacterial activity against Streptococcus mutans $(\mathrm{Sm})$, Staphylococcus aureas $(\mathrm{Sa}), \quad$ Pseudomonas aeruginosa $(\mathrm{Pa})$ and Escherichia coli $(\mathrm{Ec})$ were determined following the standard procedures4. 


\section{Assessment of antibacterial and antifungal activity}

In order to assess the biological significance and antifungal ability of the fruits of selected plants, the minimum inhibitory activity was determined by Agar Well Diffusion method4. Potato Dextrose Agar plates were prepared and selected test organisms [Candida albicans (Ca) and Aspergillus niger (An)] were seeded in the medium in petriplates. Wells of approximately $10 \mathrm{~mm}$ were bored using a well cutter and samples were added in three different concentrations ie. $25 \mu \mathrm{l}, 50 \mu \mathrm{l}$ and $100 \mu \mathrm{l}$. The petriplates were then incubated at $37^{\circ} \mathrm{C}$ for $24 \mathrm{hrs}$. The antifungal activity was assayed by measuring the diameter of the inhibition zone formed around the well. The zone of inhibition was measured in centimetres after overnight incubation and compared with clotrimazole, a standard antibiotic. Clotrimazole is used to treat skin infections such as athlete's foot, jock itch, ringworm, and other fungal skin infections.

Table I Antifungal activities of ethanolic extracts of selected fruits
Activity against selected bacteria, Streptococcus mutans, Staphylococcus aureas, Pseudomonas aeruginosa and Escherichia coli were determined following the same method using Muller Hinton medium and compared with gentamycin (control). All the chemicals used for the present study were of analytical grade.

\section{Results}

Antimicrobial (antibacterial and antifungal) assays were carried out using the ethanolic extracts of the fruits of M.alba, P.edulis and F.racemosa using selected bacteria and fungus. The results showed that among the tested fruits, the fruit extracts of M.alba inhibited the growth of all the studied fungi (Table 1) and bacteria (Figure 1) which reveals that these fruits have significant antimicrobial activity (Plate $1)$.

\begin{tabular}{lllllllllllll}
\hline Organisms & \multicolumn{1}{l}{ Concentration of extract $(\boldsymbol{\mu l})$} & \multicolumn{3}{l}{ Clotrimazole (Zone of inhibition in cm) } \\
\hline & \multicolumn{1}{l}{ Morus alba } & \multicolumn{3}{l}{ Passiflora edulis } & \multicolumn{3}{l}{ Ficus recemosa } \\
\hline & 25 & 50 & 100 & 25 & 50 & 100 & 25 & 50 & 100 \\
Candida albicans $(\mathrm{Ca})$ & - & $\mathrm{I}$ & 1.2 & - & - & - & - & - & 1.3 & 4 \\
Asperigillus niger (An) & - & - & 1.4 & - & - & - & - & - & - & 2 \\
\hline
\end{tabular}

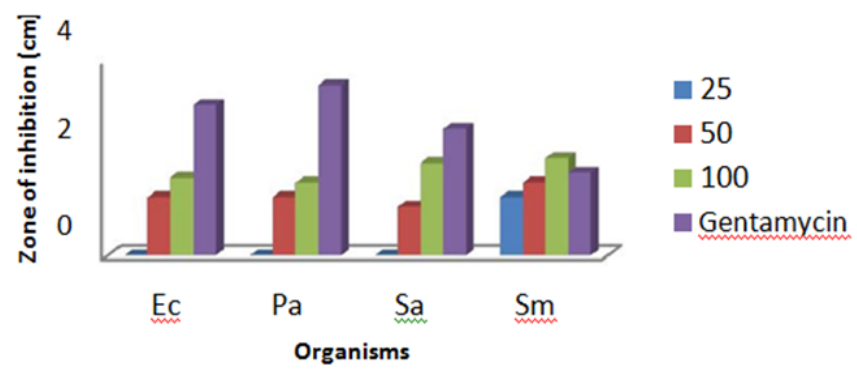

Figure I Antibacterial activities of ethanolic fruit extracts of Morus alba.

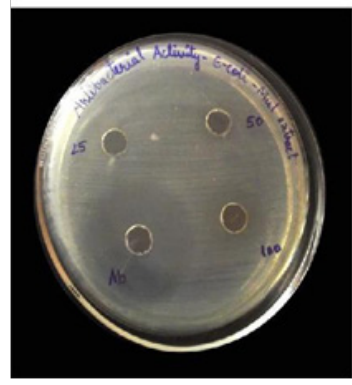

Plate IA

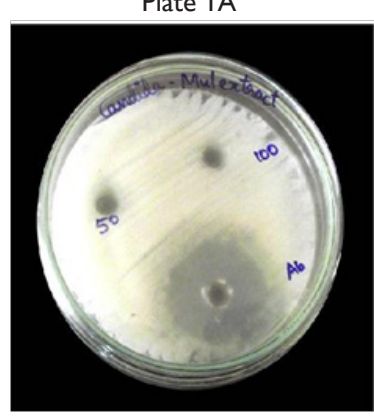

Plate ID

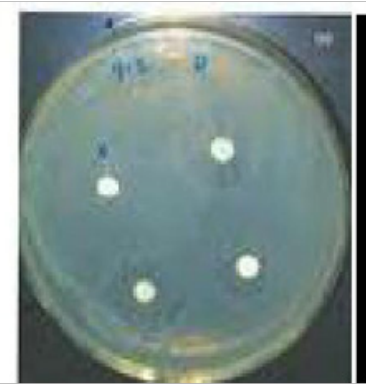

Plate IB

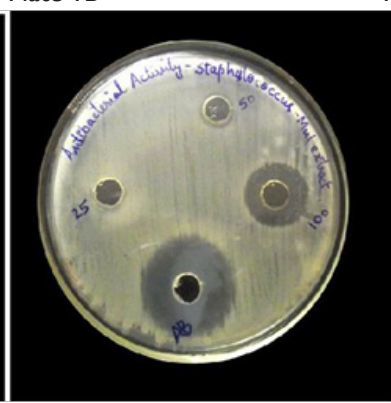

Plate IE

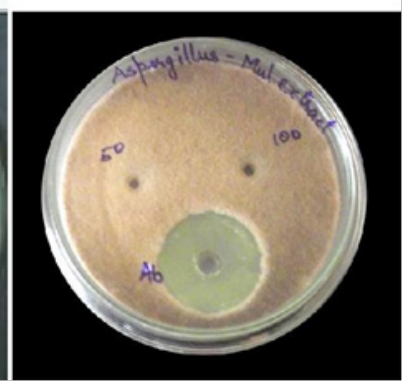

Plate IC

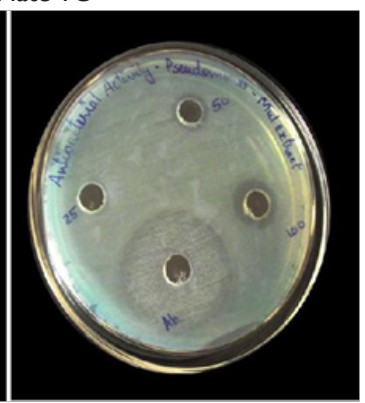

Plate IF

Plate I Antibacterial and antifungal activities of Morus alba fruits. 
Morus alba inhibited the growth of $\mathrm{Ca}$ and $\mathrm{An}$ even though the rate of inhibition was lesser than the control clotrimazole. P.edulis did not inhibit the growth of any studied fungi at lower concentrations. F.recemosa inhibited the growth of only $\mathrm{Ca}$ at $100 \mu \mathrm{l}$. Morus alba inhibited the growth of $E c$ and $S a$ at $100 \mu 1$ (Figure 2). F.recemosa does not have any effect on $\mathrm{Sa}$ but it inhibited the growth of $E c, P a$ and $S m$ at $100 \mu 1$ (Figure 3). P.edulis inhibited the growth of all the studied organisms even though the inhibition rate was lesser than gentamycin but the rate of inhibition was found to be increasing with concentration.

It was also found that antifungal activity of fruit extracts were lesser than the antibacterial activity. Inhibitory action was lesser than the control drugs. From the results it is clear that the ethanolic extracts of the studied fruits possess bacterial and fungal growth inhibition

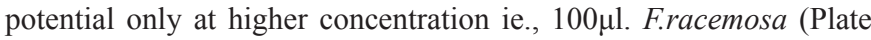
3B) and M.alba (Plate 1D) inhibited growth of Candida albicans whereas P.edulis did not showed the property (Plate 2B). Aspergillus niger was resistant to P.edulis (Plate 2B). F.racemosa fruit extract showed lesser inhibition for the growth of Streptococcus mutans and Staphylococcus aureus (Plate 3(A\&C)) but P.edulis inhibited the growth of Streptococcus mutans considerably (Plate 2C). From the results, M. alba was found to be more effective against Streptococcus mutans than Gentamycin, the control drug (Plate 1B). All the three fruit extracts inhibited the growth of Escheritia coli, the gram negative bacteria.

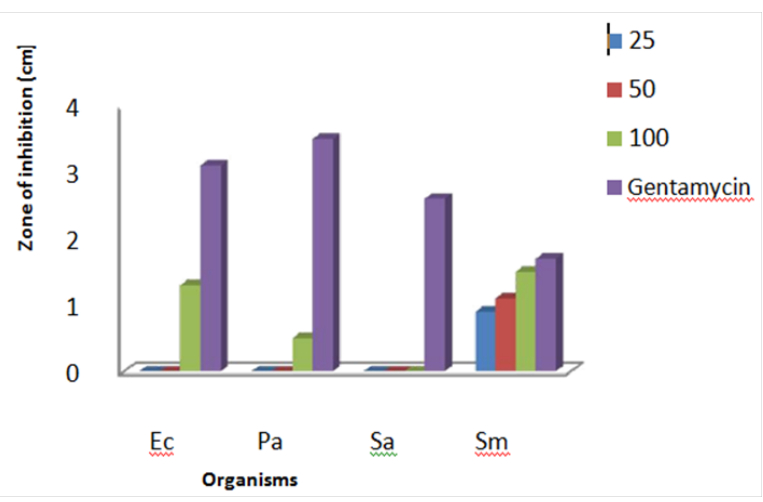

Figure 2 Antibacterial activity by Ficus recemosa.

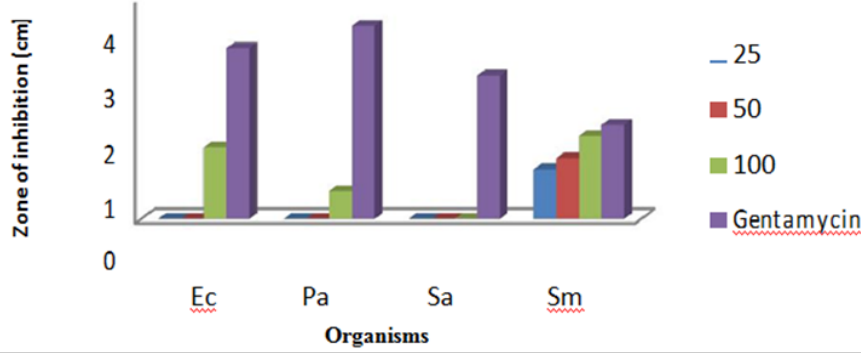

Figure 3 Antibacterial activity by Passiflora edulis.

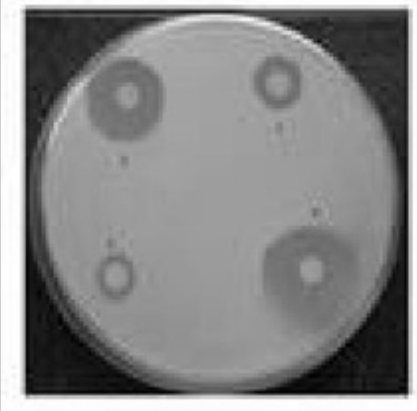

Plate 2A

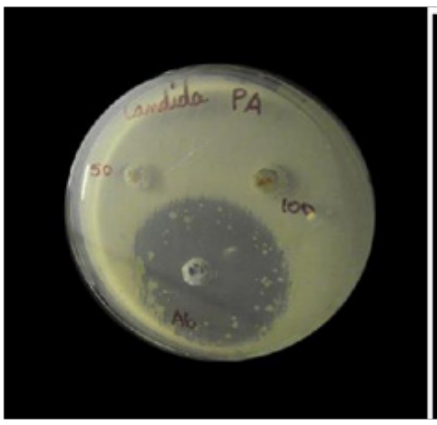

Plate 2D

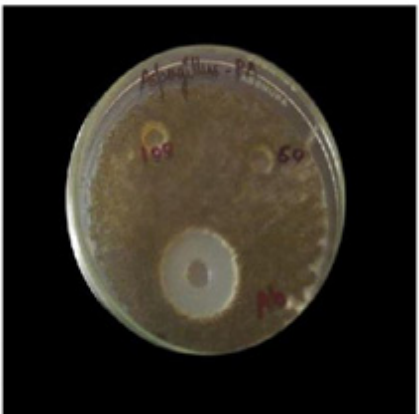

Plate 2B

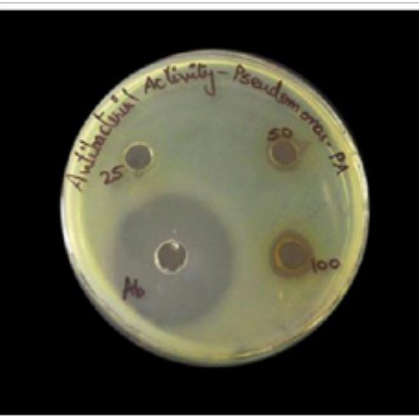

Plate 2E

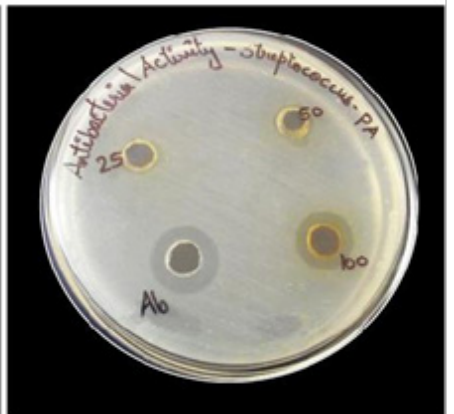

Plate $2 \mathrm{C}$

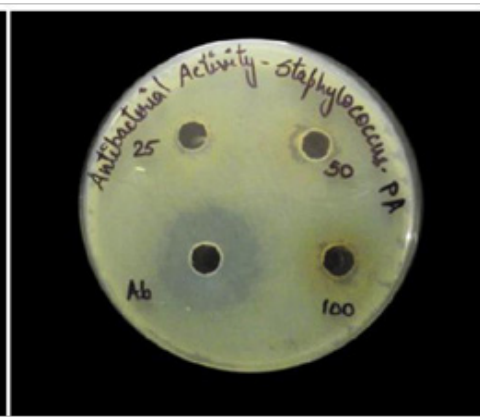

Plate 2F

Plate 2 Antibacterial and antifungal activities of Passiflora edulis fruits. 


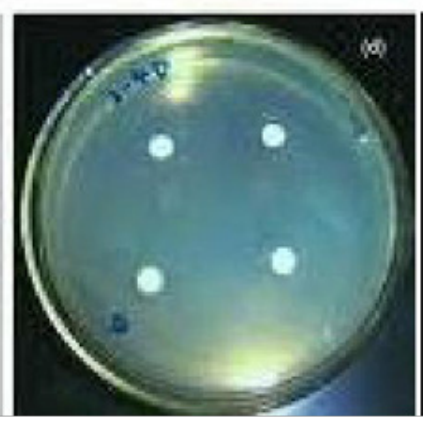

Plate 3A

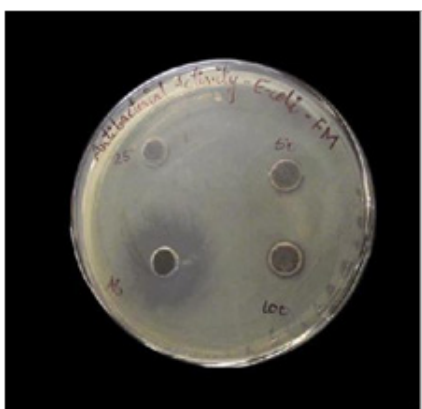

Plate 3D

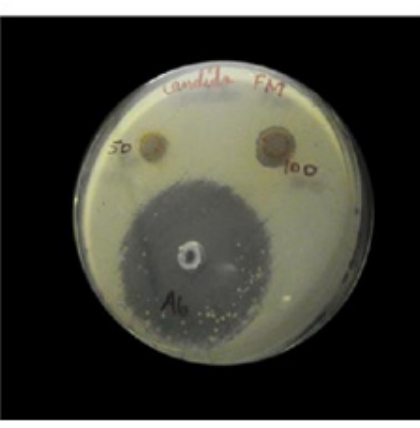

Plate 3B

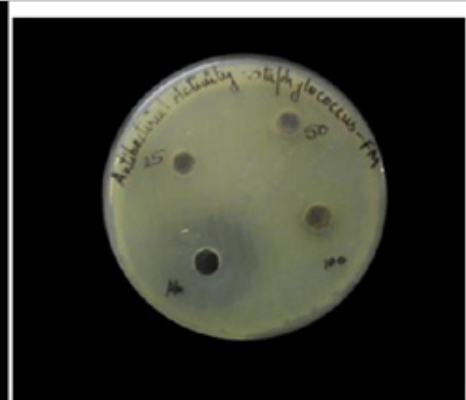

Plate 3E

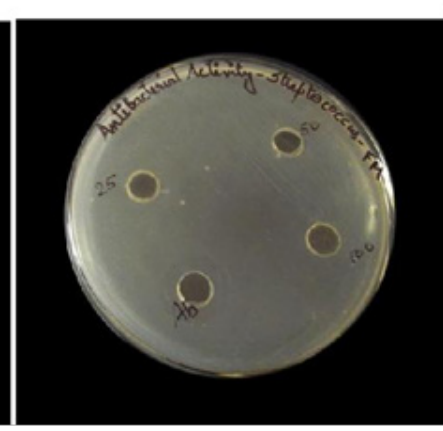

Plate $3 \mathrm{C}$

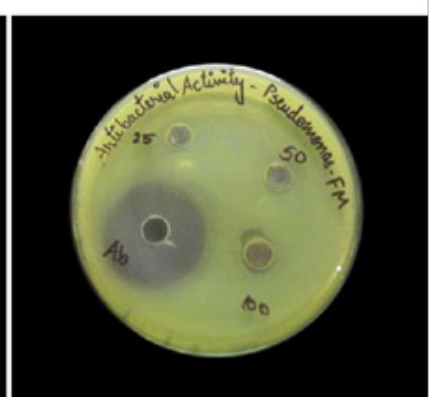

Plate 3F
Plate3 Antibacterial and antifungal activities of Ficus racemesa fruits.

\section{Discussion}

Studies by Vonshak et al., ${ }^{5}$ reported inhibitory action of $F$. racemosa and $M$. alba against $C a$. Kumar et al., ${ }^{6}$ which agrees with the results of the present study. JagtapSupriya ${ }^{7}$ also reported that methanolic extract of Fracemosa bark exhibited antimicrobial activity against Bacillus subtilis. Johnson et al., ${ }^{8}$ also reported varied effect of P.edulis to different microbes which was related to the results of present study. Ofentse et al., ${ }^{9}$ reported antibacterial activity for the stem of Morusnigra. Studies by Ayoolal et al., ${ }^{10}$ showed that ethanolic extract of $M$. alba leaves have antimicrobial potency against nocosomial infection.

Prustiet al., ${ }^{11}$ reported that, in-vitro antimicrobial activity of three plants, Litseaglutinosa, Vitexquadrilaris, Elephantopusscabra against urinary tract infection caused by Stephylococcusaureas, Pseudomonas sps. andProteus mirabilis. According to Girijashankar and Thayumanavan ${ }^{12}$ the cold water extract (10\%) of Lawsoniainermis leaf showed $70 \%$ inhibition of Rhizodoniasolani, and methanolic extract $(2.5 \%)$ completely inhibited the growth of Pythiumaphanidermatum. Yogisha et al., ${ }^{13}$ studied antibacterial activity of five plant species and observed that methanolic extracts of all the studied plants have significant activity against all the tested bacteria followed by ethyl acetate and chloroform extracts.

Antibacterial evaluation of Betulautilis by Kumaraswamy et al., ${ }^{14}$ revealed that methanolic extract showed significant activity against studied organisms followed by ethanolic extract whereas chloroform and petroleum ether extracts did not show any activity. Studies by Sermakkani et al., ${ }^{15}$ showed that methanolic extracts of leaves of Martynia annua $L$. possessed more antibacterial activity than chloroform and ethyl acetate extract. Pandal et al., ${ }^{16}$ evaluated the antimicrobial activity of leaves and bark of Vitexnegundo L. against gram positive and gram negative bacteria and reported that ethanolic and methanolic extracts of the leaves showed inhibition activity against both gram positive and gram negative bacteria whereas petroleum ether and chloroform extracts of bark had better activity against gram negative bacteria.

\section{Conclusions}

Antimicrobial activity of plant extracts are due to different bioactive chemical agents which were classified as active microbial compound. In search of safe and new antimicrobial sources, Morus alba, Passiflora edulis and Ficus recemosa were screened for their antimicrobial potency. This comparative study on selected tropical fruit extracts showed that among the tested fruits, the fruit extracts of Morus alba inhibited the growth of all the studied fungi and bacteria, proving that these fruits have significant antimicrobial activity. Microbial infections as well as resistance to antibiotics are increasing day-by-day leading to the need of new and safe sources of antibiotics. Plant based antibiotics, which are eco-friendly will be safer than synthetic antibiotics. Thus the result provides a relevant data for the society.

\section{Acknowledgments}

None.

\section{Conflicts of interest}

The author declares there is no conflicts of interest.

\section{References}

1. Foerster O. No Beitrage zur Pathophysiologie der Sehbahn und der Sehsphare. J Psychol Neurol. 1929;(39):463-485. 
2. Tassiker GE. inventor. Retinal stimulator. US patent. 1956;2760483.

3. Brindley GS, Lewin WS. The sensations produced by electrical stimulation of the visual cortex. J Physiol. 1968;(196):479-493.

4. Chuang AT, Margo CE, Greenberg PB. Retinal implants: a systematic review. Br J Ophthalmol. 2014;98(7):852-856.

5. Stingl K, Bartz-Schmidt KU, Besch D, et al. Artificial vision with wirelessly powered subretinal electronic implant alpha-IMS. Proc Biol Sci. 2013;280(1757):20130077.

6. Rizzo JF. Update on retinal prosthetic research: the Boston Retinal Implant Project. J Neuroophthalmol. 2011;31(2):160-168.

7. Roessler G, Laube T, Brockmann C, et al. Implantation and explantation of a wireless epiretinal retina implant device: observations during the EPIRET3 prospective clinical trial. Invest Ophthalmol Vis Sci. 2009;50(6):3003-3008.

8. Menzel-Severing J, Laube T, Brockmann C, et al. Implantation and explantation of an active epiretinal visual prosthesis: 2-year followup data from the EPIRET3 prospective clinical trial. Eye (Lond). 2012;26(4):501-509.

9. Matthaei M, Zeitz O, Keserü M, et al. Progress in the development of vision prostheses. Ophthalmologica. 2011;225(4):187-192.
10. Torab K, Davis TS, Warren DJ, et al. Multiple factors may influence the performance of a visual prosthesis based on intracortical microstimulation: nonhuman primate behavioural experimentation. $J$ Neural Eng. 2011;8(3):35001.

11. Bi A, Cui J, Ma Y-P, et al. Ectopic expression of a microbial-type rhodopsin restores visual responses in mice with photoreceptor degeneration. Neuron. 2006;50(1):23-33.

12. Peterman MC, Mehenti NZ, Bilbao KV, et al. The Artificial Synapse Chip: a flexible retinal interface based on directed retinal cell growth and neurotransmitter stimulation. Artif Organs. 2003;27(11):975-985.

13. Humayun MS, Dorn JD, da Cruz L, et al. Interim results from the international trial of Second Sight's visual prosthesis. Ophthalmology. 2012;119(4):779-788.

14. Da Cruz L, Coley BF, Dorn J, et al. The Argus II epiretinal prosthesis system allows letter and word reading and long-term function in patients with profound vision loss. Br J Ophthalmol. 2013;97(5):632-636.

15. Rizzo S, Belting C, Cinelli L, et al. The Argus II Retinal Prosthesis: 12-month outcomes from a single-study center. Am J Ophthalmol. 2014;157(6):1282-1290.

16. Chopdar A, Chakravarthy U, Verma D. Age related macular degeneration. BMJ. 2003;326(7387):485-488. 